\title{
A NEW LOW-EXPANSION COMPOSITE IN LEAD IRON NIOBATE-LEAD TITANATE SYSTEM
}

\author{
V.V.S.S. SAI SUNDAR and A. M. UMARJI* \\ Materials Research Centre, Indian Institute of Science, Bangalore - 560 012, \\ India
}

(Received 3 June 1996; In final form 30 August 1996)

\begin{abstract}
A composite prepared between lead titanate (PT) and lead iron niobate (PFN) exhibits low thermal expansion coefficient $(\alpha)$ over the temperature range $300-673 \mathrm{~K}$. X-ray, DTA, and dilatometric measurements have been used to identify the optimum sintering condition, retaining the individual constituent identity, to achieve overall low bulk thermal expansion. The composite, $\mathrm{PFN}_{0.35} \mathrm{PT}_{0.65}$ sintered at $1223 \mathrm{~K}$ for $15 \mathrm{~min}$. and at $1253 \mathrm{~K}$ for $60 \mathrm{~min}$. are sufficiently dense and show an overall $\alpha$ of $-0.3 \times 10^{-6} / \mathrm{K}$ and $-1.2 \times 10^{-6} / \mathrm{K}$, respectively, in the temperature range $300-673 \mathrm{~K}$.
\end{abstract}

\section{INTRODUCTION}

Low or controlled thermal expansion ceramics cover a wide range of applications from cookware to space structures. Recently, low-expansion ceramic material, like cordierite has even been used as a packaging material for integrated circuits ${ }^{1}$. Several strategies have been adopted in the literature to look for compounds or composites exhibiting controlled/low thermal expansion region over a limited temperature range ${ }^{2}$. These investigations include (i) Search for compounds with special structural features, e.g., $\mathrm{NaZr}_{2} \mathrm{P}_{3} \mathrm{O}_{12}$ family ${ }^{3}, \mathrm{Mg}_{2} \mathrm{Al}_{4} \mathrm{Si}_{5} \mathrm{O}_{18}$ type of materials ${ }^{4}$, and LiAl$\mathrm{Si}_{\mathrm{x}} \mathrm{O}_{12}{ }^{5}$. All these compounds have a skeleton framework built up of covalently bonded, highly charged cation polyhedra $\left(\mathrm{Si}^{4+}, \mathrm{P}^{5+}, \mathrm{Al}^{3+}\right.$ etc.)

*Corresponding author. 
and channels, rings, and cavities wherein the thermal ellipsoids can expand, ii) Chemical substitution of the selected cation site in the known low-expansion systems with the hope of improving the properties like thermal expansion anisotropy, thermal shock resistance, e.g., family of NASICON compounds ${ }^{6}$, substituted cordierite ceramics ${ }^{7-9}$, iii) Use of the electronic phase transitions as in the $\mathrm{Pb}\left(\mathrm{Fe}_{1 / 2} \mathrm{Nb}_{1 / 2}\right) \mathrm{O}_{3}$ to generate lowexpansion behavior over a limited temperature range ${ }^{10}$, iv) Make composites with material having negative and positive thermal expansion coefficients $(\alpha)$ in order to produce a bulk ceramic with a net low thermal expansion coefficient ${ }^{11}$. This paper presents the preparation of the low expansion composite between lead iron niobate and lead titanate by adopting the last mentioned approach.

Lead iron niobate (PFN) has a rhombohedral structure (space group $\mathrm{Pm} 4 \mathrm{~m}$ ) at room temperature with a relaxor ferroelectric $\mathrm{T}_{\mathrm{c}}$ of $385 \mathrm{~K}^{12}$. The lattice parameters are $\mathrm{a}=4.014 \AA$ and $\beta=89.92^{\circ}$, and for all practical purposes the structure is considered to be pseudocubic. It exhibits a low expansion region $\left(\alpha=1.3-1.5 \times 10^{-6} / \mathrm{K}\right)$ up to its $\mathrm{T}_{\mathrm{c}}$, and shows a high thermal expansion coefficient $\left(\alpha=11-12 \times 10^{-6} / \mathrm{K}\right)$ beyond it. Lead titanate $^{13}$ has a tetragonal structure (space group $\mathrm{P} 4 / \mathrm{mmm}$ ) at room temperature, which undergoes a structural phase transition to a cubic structure at $763 \mathrm{~K}$. Lead titanate (PT) shows contraction up to $763 \mathrm{~K}$ and expansion beyond, as observed both in the high temperature x-ray diffraction and dilatometric studies.

Our recent investigations of the PFN-PT system, showed that a complete solid solution exists between them ${ }^{14}$. The room temperature structure changed over from pseudocubic to tetragonal for $\mathrm{x}$ values between 0.1 to 0.2 in the $\mathrm{PFN}_{1-\mathrm{x}} \mathrm{PT}_{\mathrm{x}}$ system. A systematic variation of c/a ratio from $0 \%$ to $6 \%$ and $\mathrm{T}_{\mathrm{c}}$ from $385 \mathrm{~K}$ to $763 \mathrm{~K}$ was observed with the increase of lead titanate content. The dilatometric data is shown for some members of the family in fig. 1 . The pseudocubic members showed a low expansion coefficient up to $T_{c}$, whereas tetragonal compositions showed a contraction below $\mathrm{T}_{\mathrm{c}}$. In the cubic region, however, $\alpha$ attained a value of about 10-11 $\times 10^{-6} / \mathrm{K}$. The lowering of tetragonal distortion, in turn, lowered the negative contraction exhibited up to the $T_{c}$ in the compositions with tetragonal distortion. This resulted in obtaining materials with different amount of contraction up to different temperatures.

The availability of materials with negative and positive expansion coefficients up to different temperatures was the basis of making appropriate 


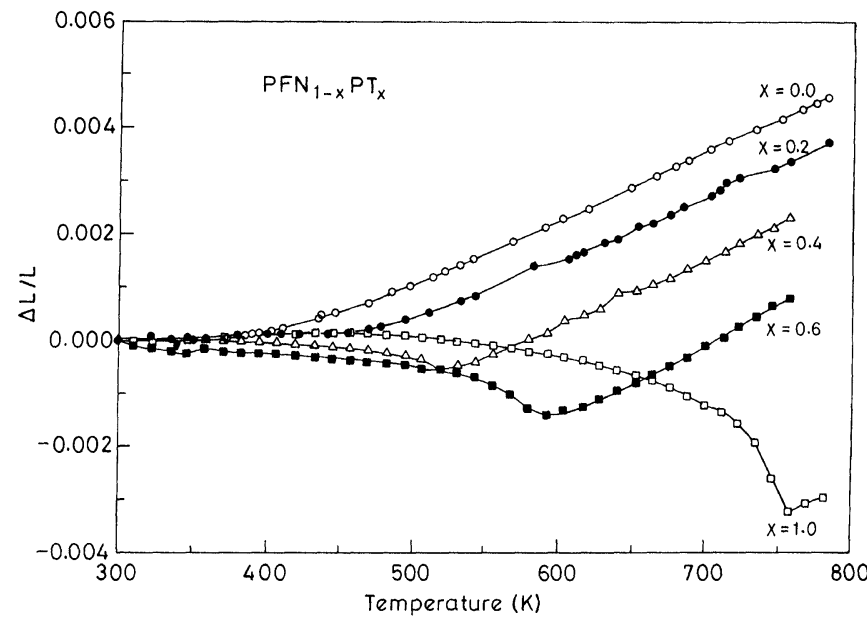

FIGURE $1 \Delta \mathrm{L} / \mathrm{L}$ variation with temperature in the PFN-PT system.

composites and investigations if zero/low thermal expansion could be achieved. The main task was to find out the sintering condition at which the individual identity of each member of the composite was maintained but sufficient sintering occurred, in order to get reasonable sinter density and overall low bulk expansion. In this paper, we report the optimum sintering condition and thermal expansion behavior of a composite prepared from the well-characterized compositions in the solid solutions of $\mathrm{PFN}_{1-\mathrm{x}} \mathrm{PT}_{\mathrm{x}}$.

\section{EXPERIMENTAL}

\section{a. Synthesis}

The individual components were prepared by using the solid state method of calcining the stoichiometric proportions of high-purity oxides at $1173 \mathrm{~K}$ for $1 \mathrm{hr}$., followed by a subsequent sintering in pellet form at $1223-1253 \mathrm{~K}$ $1 \mathrm{hr}$. depending on the value of $\mathrm{x}$ in the $\mathrm{PFN}_{1-\mathrm{x}} \mathrm{PT}_{\mathrm{x}}$ system ${ }^{14}$. Proper care was taken in order to compensate the $\mathrm{PbO}$ loss during the sintering and firing stages. A composite $\mathrm{C} 1$, of $\mathrm{x}=0.4,0.6$, and 1.0 (by taking equal weights of solid solutions) was prepared by hand mixing the well-formed 
individual solid solutions in the acetone medium. PVA was used as a binder for making the pellet. Slow heating up to $823 \mathrm{~K}$ was adopted to burn off the binder and also to avoid intentional porosity that arises due to rapid heating, which, in turn, reduces the strength of the ceramic body. The samples were subjected to different heat treatments at 1073K (C1-1073), 1173K (C1-1173), 1223K (C1-1223), and 1373K (C1-1323K) for $15 \mathrm{~min}$. or $60 \mathrm{~min}$. The results of this study was utilized to identify the optimum sintering condition of the desired composite, in order to get sufficient sinter density but still retain individual characteristics of the individual compositions/constituents.

Using the TEC data of PFN and PT, a composite with composition $\mathrm{PFN}_{0.5} \mathrm{PT}_{0.5}$ (C2) (i.e., 50 mole \% of PFN +50 mole $\%$ of PT) and $\mathrm{PFN}_{0.35} \mathrm{PT}_{0.65}$ (C3) was calculated to have net low expansion over the wide range of temperature $(300-800 \mathrm{~K})$. The above chosen composite compositions were prepared by mixing well characterized PFN and PT in their molar ratio in the acetone medium. The compacted pellets were sintered at $1223 \mathrm{~K}(\mathrm{C} 2-1223, \mathrm{C} 3-1223)$ and $1253 \mathrm{~K}(\mathrm{C} 2-1253, \mathrm{C} 3-1253)$ for $15 \mathrm{~min}$. or $60 \mathrm{~min}$. respectively. These sintering times and temperatures were chosen from the behavior of the $\mathrm{C} 1$ series of the composites.

\section{b. Characterization}

Room temperature $\mathrm{x}$-ray patterns were recorded on a Scintag powder diffractometer (Scintag, XDS, with Ge solid-state detector) using $\mathrm{Cu} \mathrm{K}_{\alpha}$ radiation at a scanning speed of $0.25^{\circ} / \mathrm{min}$. Dilatometric data was collected using a home-built dilatometer ${ }^{15}$ with a sensitivity of $\Delta \mathrm{L} / \mathrm{L}=10^{-7}$ for a sample length $6-10 \mathrm{~mm}$. Differential thermal analysis curves were recorded on the simultaneous thermal analyzer (Polymer Laboratories, STA1500) at a ramping rate of $10^{\circ} \mathrm{K} / \mathrm{min}$. Densities were measured by the Archemides technique using a density kit (Metler, Model AE240).

\section{RESULTS AND DISCUSSION}

\section{a. Three Component Composite in the $\mathbf{P F N}_{1-x} \mathbf{P T}_{x}$ System}

The x-ray diffractograms recorded at $0.25 \% \mathrm{~min}$. scanning speeds between $31-33^{\circ}$ and $43-48^{\circ}$ two theta ranges are shown in fig. 2 for $\mathrm{C} 1$ series 


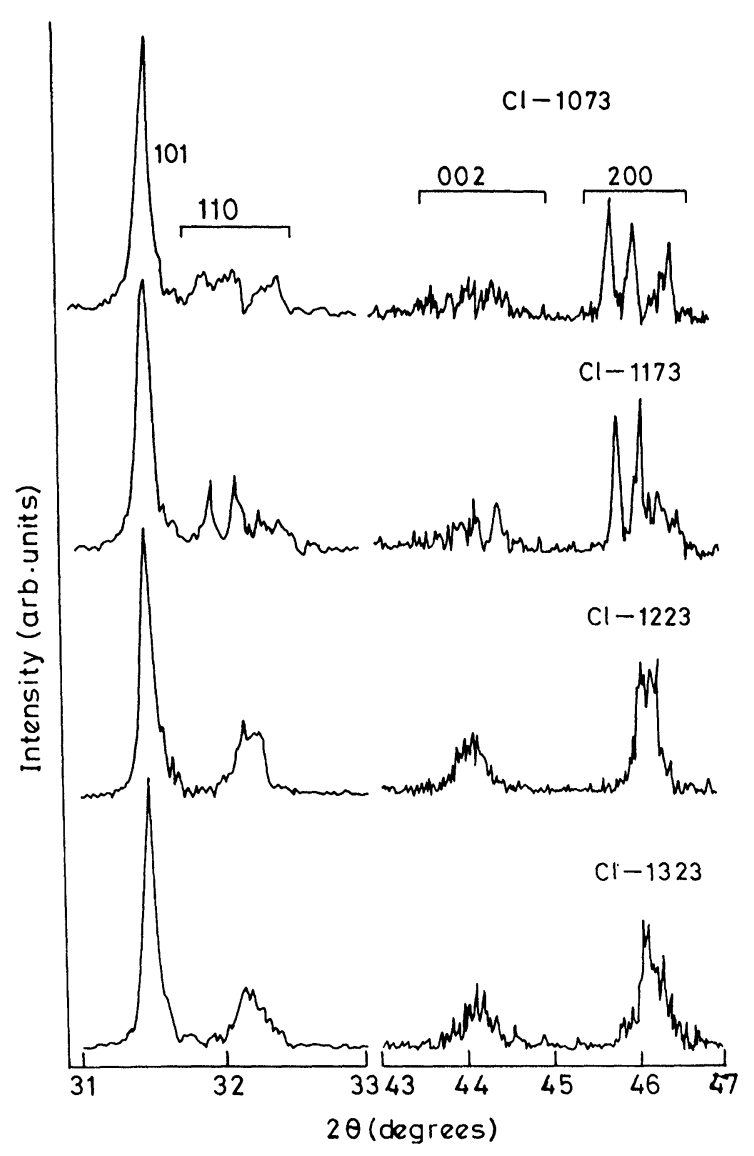

FIGURE 2 Room temperature $\mathrm{x}$-ray pattern of $\mathrm{C} 1$ composites heated to different temperatures.

samples heat treated at different temperatures. The strong peak at $31.48^{\circ}$ for C1-1073 is due to overlap of the 101 peak of the three constituents, i.e., $\mathrm{PbTiO}_{3}, \mathrm{PFN}_{0.4} \mathrm{PT}_{0.6}$, and $\mathrm{PFN}_{0.6} \mathrm{PT}_{0.4}$. The 110 peaks of individual phases are observed at a two theta of $31.91^{\circ}, 32.12^{\circ}$ and $32.42^{\circ}$, respectively. Similarly, the 200 peaks at $45.80^{\circ}, 46.06^{\circ}$, and $46.48^{\circ}$ are clearly seen for the respective phases. The pattern for $\mathrm{C} 1-1173$ shows that 110 , 002, and 200 peaks due to $\mathrm{PbTiO}_{3}$ started disappearing on heating to higher temperatures. The pattern for $\mathrm{C} 1-1223$ shows a single broad 110 peak and broad peaks corresponding to 002 and 200 . The position of these peaks remain the same in $\mathrm{C} 1-1323$ except that the peaks become narrower. 
The C1-1323 pattern corresponds to the emergence of single solid solution with a c/a ratio of 1.403. From the known behavior of c/a versus $\mathrm{x}^{14}$, this c/a corresponds to a composition of $\mathrm{PFN}_{0.56} \mathrm{PT}_{0.44}$, which is in close agreement to the expected average of cation concentration of the three constituent phases. The $\mathrm{x}$-ray studies indicate that formation of a single phase solid solution begins slightly below heat treatment at $1223 \mathrm{~K}$ for 60 min. Below this temperature, the three individual phases are identified. Another batch of C1-1223, heat treated for only 15 minutes, was used for further studies. Further confirmation of these conclusions is derived from the DTA studies.

Fig. 3 shows the DTA curves recorded on both heating and cooling cycle of C1-1073, C1-1173, and C1-1223 samples. Table I gives the transition temperatures and the area under the curve estimated from DTA studies. The composite C1-1073 clearly showed an endothermic peak at $753 \mathrm{~K}$, $593 \mathrm{~K}$, and $523 \mathrm{~K}$ indicating the existence of the individual solid solutions. The peak at $523 \mathrm{~K}$ is very weak due to low heat of transition. No phase transition could be seen for the C1-1223 sample. The endothermic peak position and the relative peak area agree well with the behavior reported earlier by us $^{14}$ for individual solid solutions. The C1-1173 sample also show endothermic peaks at $753 \mathrm{~K}$ and $593 \mathrm{~K}$ and no detectable transition at $523 \mathrm{~K}$. The area under the peak should represent the amount of discrete component of the composite intact as a function of heat treatment temperature. The area under the curve due to $763 \mathrm{~K}$ transition of PT decreases from $0.38 \mu \mathrm{v} \mathrm{sec} / \mathrm{mg}$ of $\mathrm{C} 1-1073$ to $0.29 \mu \mathrm{v} \mathrm{sec} / \mathrm{mg}$ for $\mathrm{C} 1-1173$ and this transition is not observable for C1-1223. A similar decrease in the area under the curve for $593 \mathrm{~K}$ due to the $\mathrm{x}=0.6$ solid solution is also observed. Upon sintering at $1323 \mathrm{~K}$ for $60 \mathrm{~min}$., the DTA curves indicate a single phase transition at $575 \mathrm{~K}$ with an area of $0.23 \mu \mathrm{v} \mathrm{sec} / \mathrm{mg}$ corresponding to a homogenous solid solution of $\mathrm{x}$ approximately equal to 0.4 .

The variation of phase transition temperature as a function of $\mathrm{x}$ for a single-phase, solid-solution of the system $\mathrm{PFN}_{1-\mathrm{x}} \mathrm{PT}_{\mathrm{x}}$ along with c/a ratio is shown in fig. 4. By knowing the transition temperature or the c/a ratio, this graph can be used to get the composition or vice versa. The phase transition temperatures of the composite $\mathrm{C} 1-1323$ heated for $60 \mathrm{~min}$. is at $575 \mathrm{~K}$, which corresponds to $\mathrm{x}=0.4$, and should have a c/a ratio 1.04 . This is in agreement with the observed c/a ratio of 1.043 obtained from $\mathrm{x}$-ray diffraction pattern of the same sample. 


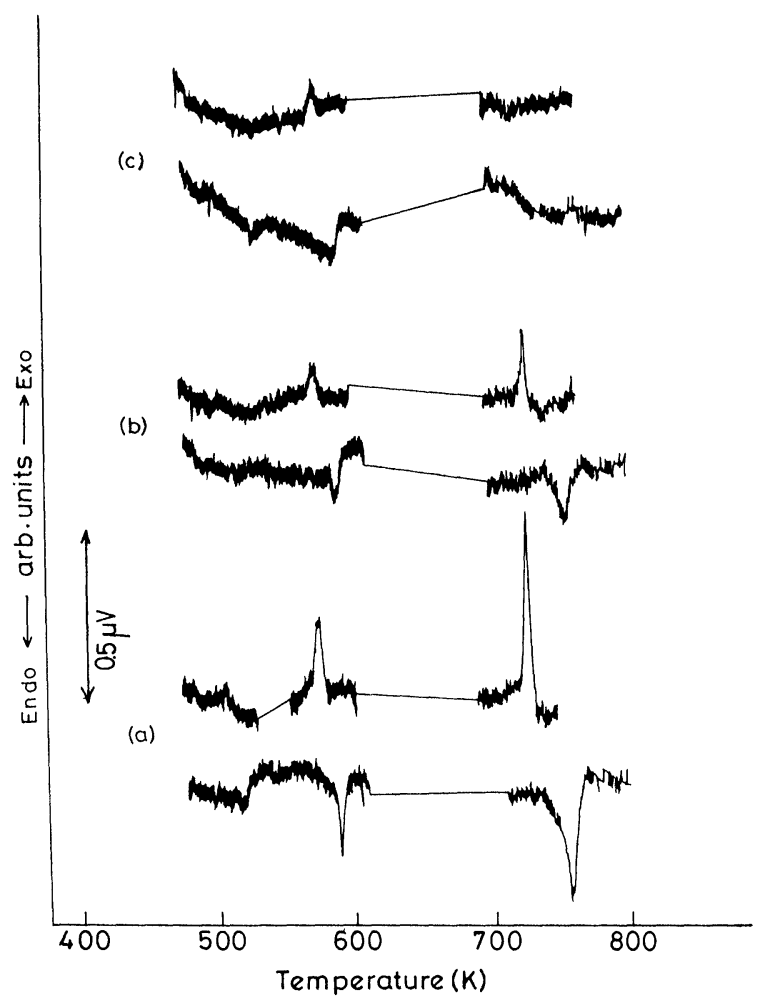

FIGURE 3 The heating and cooling DTA curves for the C1-1073 (15 min.), C1-1173 (15 min.) and C1-1223 (60 min.) composites.

Densities of the pellets used for dilatometric measurements were $>$ 90\% (Table I). The C1-1073 composite showed relatively low density values $(91 \%)$ as the compact could not have sintered sufficiently. Density values attained a maximum of 93.57 for $\mathrm{C} 1-1223$, and instead of a further increase at higher heat treatment temperatures, density reduced to $91 \%$ for C1-1323. This reduction was due to the formation of the solid solution. These results show that $\mathrm{C} 1-1223$ sintered for $15 \mathrm{~min}$. or $60 \mathrm{~min}$. does not show DTA signature of any phase transition and the maximum density can be achieved at this sintering temperature. 
TABLE 1 Sintered pellet densities and DTA results for $\mathrm{PFN}_{1-\mathrm{x}} \mathrm{PT}_{\mathrm{x}}$ solid solutions and composites

\begin{tabular}{lccccc}
\hline$x$ in $P F N_{1-x} P T_{x}$ & \% Density & $\begin{array}{c}\text { DTA peak } \\
\text { area } \\
\text { (heating) } \\
\mu v \text { sec/mg }\end{array}$ & $\begin{array}{c}T_{c} \\
(K)\end{array}$ & $\begin{array}{c}\text { DTA peak } \\
\text { area } \\
\text { (cooling) } \\
\mu v \text { sec/mg }\end{array}$ & $\begin{array}{c}T_{c} \\
(K)\end{array}$ \\
\hline 0.0 & 90.98 & - & $-{ }^{\mathrm{a}}$ & - & - \\
0.1 & 89.34 & - & - & - & - \\
0.2 & 91.31 & - & $453^{\mathrm{b}}$ & - & - \\
0.3 & 89.00 & 0.33 & 474.75 & -0.26 & 476.56 \\
0.4 & 95.99 & 0.23 & 503.01 & -0.31 & 515.81 \\
0.6 & 91.07 & 0.52 & 583.04 & -0.60 & 653.07 \\
0.8 & 93.56 & 0.72 & 670.56 & -0.75 & 670.7 \\
1.0 & 96.93 & 1.87 & 729.8 & -2.89 & 724.34 \\
C1-1073(15 min.) & 91.85 & 0.38 & 749.37 & -0.65 & 729.87 \\
C1-1173(15 min.) & 90.91 & 0.16 & 582.18 & -0.16 & 557.65 \\
& & 0.29 & 747.24 & -0.28 & 733.11 \\
C1-1223(15 min.) & 93.57 & 0.13 & 582.44 & -0.08 & 575.92 \\
C1-1223(60 min.) & 90.34 & - & - & - & - \\
C1-1323(60 min.) & 91.15 & 0.23 & 580.21 & -0.14 & 574.8 \\
C2-1223(15 min.) & 89.75 & 0.50 & 746.34 & -0.60 & 732.32 \\
C2-1253(60 min.) & 91.79 & 0.20 & 741.32 & -0.34 & 731.09 \\
C3-1223(15 min.) & 93.65 & 0.20 & 747.34 & -0.36 & 730.24 \\
C3-1253(60 min.) & 93.67 & - & - & - & - \\
\hline
\end{tabular}

aphase transition could not be detected.

${ }^{\mathrm{b}} \mathrm{T}_{\mathrm{c}}$ from DSC technique

*For composition see text; value in the parenthesis correspond to the duration of the heat treatment at respective temperature.

Fig. 5 gives the variation of $\Delta \mathrm{L} / \mathrm{L}$ versus temperature for the composite heat treated under different conditions. Unlike independent transitions as seen in DTA experiments, these composites showed the broad contraction between $573 \mathrm{~K}-773 \mathrm{~K}$. Since the three compositions selected had negative thermal expansion coefficient up to the phase transition temperature, the overall composite heated at all temperatures showed net contraction. The dilatometric measurements indirectly indicated the strength of the pellet was maximum at the optimum sintering temperature. This could be seen from the behavior of the composites C1-1073 and C1-1223 pellets. The former pellet scrambles after two cycles of data collection, whereas the later was strong even after five to six cycles. From the above studies, 


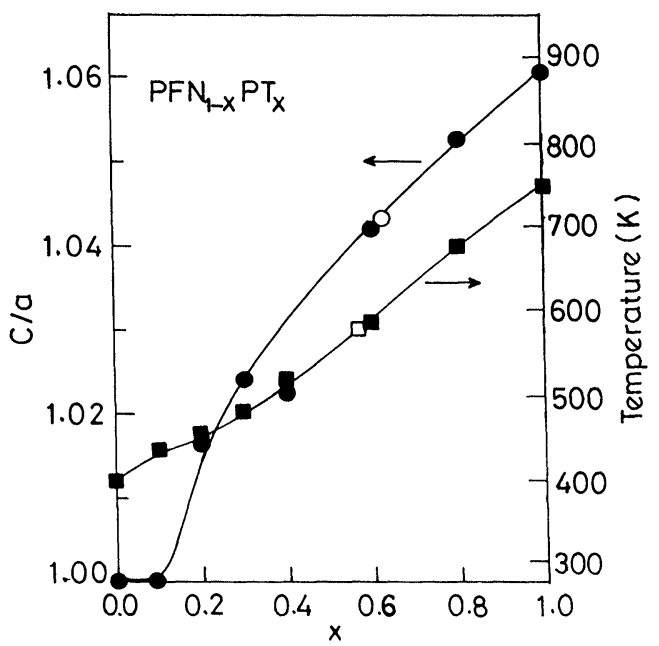

FIGURE 4 Variation of c/a ratio and transition temperature $\left(\mathrm{T}_{\mathrm{c}}\right)$ with $\mathrm{x}$ in the $\mathrm{PFN}_{1-\mathrm{x}} \mathrm{PT}_{\mathrm{x}}$ system. Open symbols are for $\mathrm{C} 1-1323$ composite.

it was found that $1223 \mathrm{~K}$ was the optimum sintering temperature for all the practical considerations. The information of sintering behavior was further used to design the required composite in the next step.

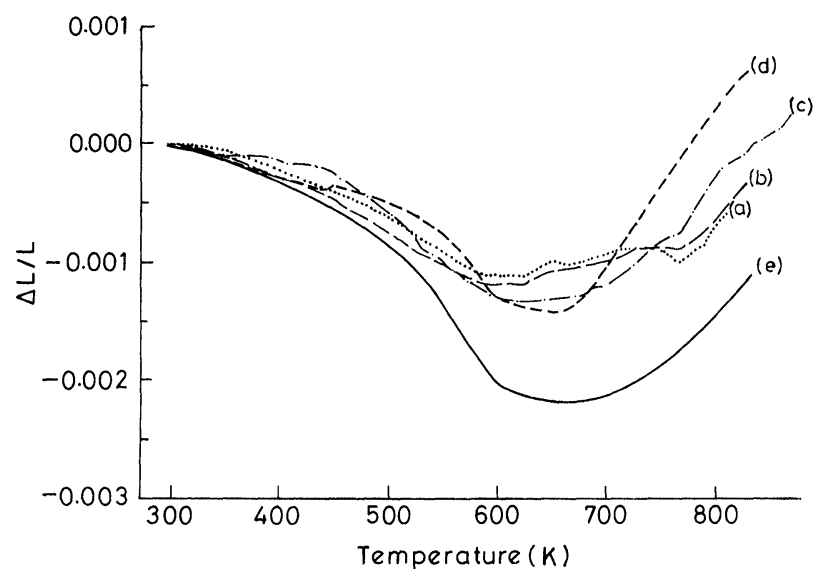

FIGURE $5 \Delta \mathrm{L} / \mathrm{L}$ variation with temperature for the composites prepared from solid solutions with $\mathrm{x}=0.0,0.4$ and 0.6 sintered at a) $1073 \mathrm{~K} / 15 \mathrm{~min}$., (b) $1173 \mathrm{~K} / 15 \mathrm{~min}$., (c) $1223 \mathrm{~K} / 15 \mathrm{~min}$., (d) $1253 \mathrm{~K} / 60 \mathrm{~min}$. and (e) $1323 \mathrm{~K} / 60 \mathrm{~min}$. respectively. 


\section{b. Low Expansion Composite from PFN and PT}

Lead titanate shows a contraction $\left(\alpha=-5.8 \times 10^{-6} / \mathrm{K}\right)$ up to the $\mathrm{T}_{\mathrm{c}}$ and expansion beyond it, and lead iron niobate has a low expansion $(\alpha=1.3$ $\left.\times 10^{-6} / \mathrm{K}\right)$ in the relaxor region up to $393 \mathrm{~K}$, and a high $\alpha$ above it $(\alpha=$ $\left.10-11 \times 10^{-6} / \mathrm{K}\right)$ (Table II). A composite of these two is expected to exhibit net low expansion over a wide temperature region. By using the $\Delta \mathrm{L} / \mathrm{L}$ data of these two compounds, the expected behavior of the intermediate composites with different mole ratio of the end members is shown in Fig. 6. Two composites, $\mathrm{C} 2\left(\mathrm{PFN}_{0.5} \mathrm{PT}_{0.5}\right)$ and $\mathrm{C} 3\left(\mathrm{PFN}_{0.35} \mathrm{PT}_{0.65}\right)$, expected to have low expansion up to $673 \mathrm{~K}$ were picked up for the preparation and further study.

The slow-scan x-ray diffractograms are shown in fig. 7 for the four composites (C2-1223, C2-1253, C3-1223, and C3-1253). The strong peak at $31.45^{\circ}$ in all cases is due to the 110 peak of PFN and 110 peak of PT, respectively. However, the 110 peak at $32.45^{\circ}$ and the peak positions of 002 and 200 peaks indicate interesting behavior. The patterns of C2-1223 and C3-1223 show additional $\mathrm{x}$-ray intensity between $31.45^{\circ}$ and $32.45^{\circ}$ peaks due to starting materials. A similar feature is observed between 002 and 200 peaks, though in this region the intensity is low and hence the

TABLE II Thermal expansion coefficients $\left(\times 10^{-6} / \mathrm{K}\right)$ of various solid solutions and composites in $\mathrm{PFN}_{1-\mathrm{x}} \mathrm{PT}_{\mathrm{x}}$ system

\begin{tabular}{lcc}
\hline$x$ in & \multicolumn{2}{c}{$\alpha$} \\
\cline { 2 - 3 } PFN $_{t-x} P T_{x}$ & $298-T_{c}$ & Above $T_{c}$ \\
\hline 0.0 & 1.3 & 11.7 \\
0.1 & 1.5 & 11.6 \\
0.2 & 0.8 & 11.4 \\
0.3 & -2.2 & 8.3 \\
0.4 & -2.5 & 12.8 \\
0.6 & -4.2 & 13.8 \\
0.8 & -9.8 & 9.7 \\
1.0 & -5.8 & 15.0 \\
C2-1223(15 min. $)^{\mathrm{a}}$ & $2.5^{*}$ & - \\
C2-1253(60 min.) & $1.4^{*}$ & - \\
C3-1223(15 min.) & $-0.3^{*}$ & - \\
C3-1253(60 min.) & $-1.2^{*}$ & - \\
\hline
\end{tabular}

*Thermal expansion coefficients are in between 298-673K.

a duration of heat treatment at the mentioned temperatures 


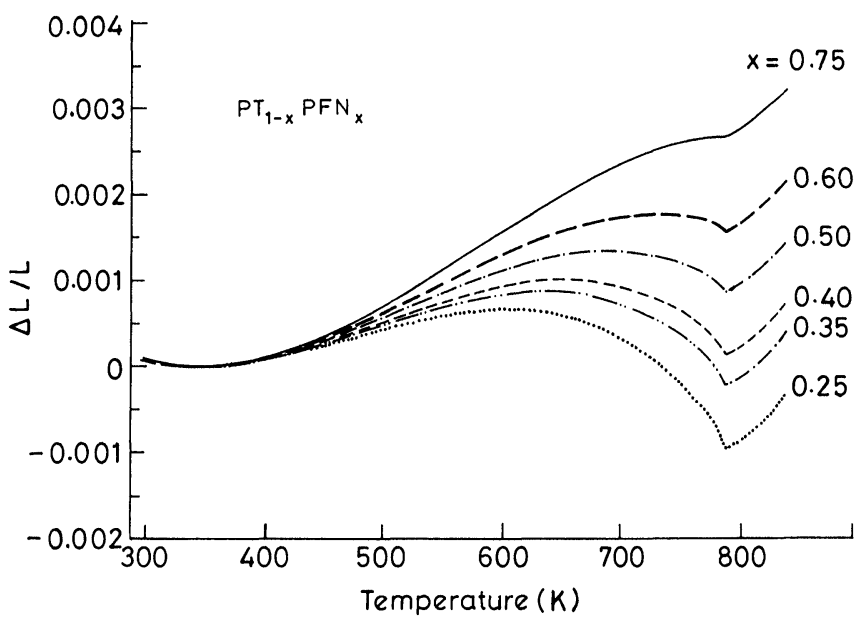

FIGURE 6 Expected behavior of $\Delta \mathrm{L} / \mathrm{L}$ for the intermediate composites in the $\mathrm{PT}_{1-\mathrm{x}} \mathrm{PFN}_{\mathrm{x}}$ system.

peaks are not well resolved. The pattern of composites C2-1253 and C31253 indicate crystallization of a single-phase solid solution corresponding to a c/a ratio of 1.0315 and 1.0414 , respectively. The peaks are broad and spectra are noisy due to insufficient heating time and poor crystallinity. Even though x-ray diffraction analysis indicate formation of a poorly crystalline solid solution at 1253 , the DTA results do not indicate any phase transition. The pellets were sufficiently strong and found to have a density of $>93 \%$ (Table I).

The $\Delta \mathrm{L} / \mathrm{L}$ plots for the four composites are shown in fig. 8. The overall $\alpha$ values between $300-773 \mathrm{~K}$ are listed in Table II. It is seen that the C2 composite have higher $\alpha$ than $\mathrm{C} 3$ composite due to higher PFN content. In both cases, heating at $1223 \mathrm{~K}$ for $15 \mathrm{~min}$. is found to give lower $\alpha$ values. The C3-1253 has the lowest $\alpha$ of $-0.37 \times 10^{-6} / \mathrm{K}$ in the temperature range $300-773 \mathrm{~K}$. All the composites showed a dip in $\Delta \mathrm{L} / \mathrm{L}$ behavior at about $770 \mathrm{~K}$, which is attributed to residual amount of $\mathrm{PbTiO}_{3}$ present. However, except for dilatometric evidence, no other supporting proof from $\mathrm{x}$-ray or DTA experiments could be found to show the existence of lead titanate. 


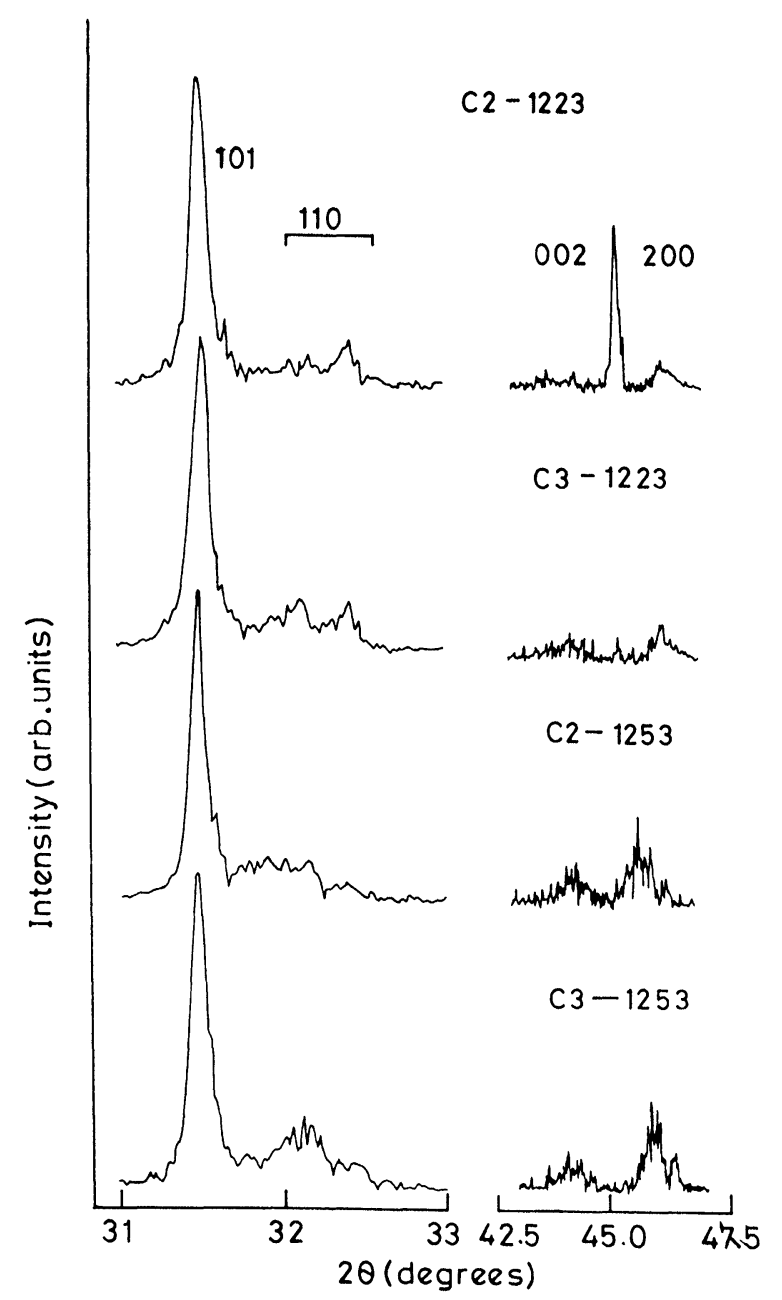

FIGURE 7 Room temperature $\mathrm{x}$-ray patterns of $\mathrm{C} 2$ and $\mathrm{C} 3$ composites.

\section{CONCLUSIONS}

In conclusion, we have shown that a suitably sintered composite between PFN and PT has low thermal expansion over a wide temperature range. Sintering between $1223-1253 \mathrm{~K}$ is optimum in producing a sufficiently 


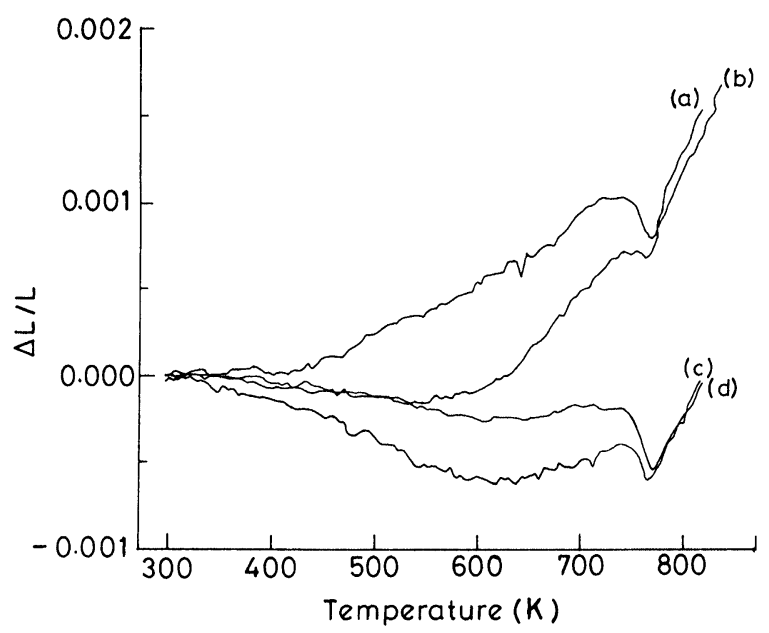

FIGURE 8 The variation of $\Delta \mathrm{L} / \mathrm{L}$ versus temperature for the composites $\mathrm{PT}_{0.5}+\mathrm{PFN}_{0.5}$ $(\mathrm{a}, \mathrm{b})$ and $\mathrm{PT}_{0.65}+\mathrm{PFN}_{0.35}(\mathrm{c}, \mathrm{d})$, heated at $1223 \mathrm{~K} / 15 \mathrm{~min}$. and $1253 \mathrm{~K} / 60 \mathrm{~min}$. respectively.

dense ceramic body in which the individual identity of constituent members is retained, and the low $\alpha$ of $-0.3 \times 10^{-6} / \mathrm{K}$ is achieved in the temperature range of $300-700 \mathrm{~K}$.

\section{Acknowledgments}

We thank Department of Atomic Energy for providing the financial assistance. One of the author (V.V.S.S.) thanks the University Grants Commission for the award of senior research fellowship.

\section{References}

[1] Tirumala, R. R. (1991). "Ceramic and Glass-Ceramic packaging in the 1990s", J. Am. Ceram. Soc., 75, 15, 895.

[2] Roy, R., Agarwal, D. K. (1985). "Successful design of new very low thermal expansion ceramics", Mat. Res. Soc. Symp. Proc., 83, 40.

[3] Roy, R., Agarwal, D. K., Alamo, J. and Roy, R. A. (1984). "[CTP]: A new structural family of near-zero expansion ceramics", Mat. Res. Bull., 19, 471.

[4] Lachman, I. M., Bagley, R. D., Lewis, R. M. (1981). "Thermal expansion of Extruded Cordierite Ceramics", Ceram. Bull., 60(2), 202.

[5] Roy, R., Roy, D. M. and Osborn, E. F. (1950). "Compositional and stability relations among the lithium aluminosilicates: eucryptite, spodumene and petalite", J. Am. Ceram. Soc., 33, 152 . 
[6] Alamo, J. and Roy, R. (1984). "Ultra-low expansion ceramics in the system $\mathrm{Na}_{2} \mathrm{O}$ $\mathrm{ZrO}_{2}-\mathrm{P}_{2} \mathrm{O}_{5}-\mathrm{SiO}_{2}$ ”, J. Am. Ceram. Soc., 67, c78.

[7] Ikawa, H., Otagiri, T., Suzuka, M., Urabe, K., Udagawa, S. (1986). "Crystal structures and mechanism of thermal expansion of high cordierite and its solid solutions", J. Am. Ceram. Soc., 69(6), 492.

[8] Agarwal, D. K., Stubican, V. S., Mahrotra, Y. (1986). "Germanium-modified cordierite ceramics with low thermal expansion", J. Am. Ceram. Soc., 69(12), 847.

[9] Sai Sunder, V. V. S. S. and Umarji, A. M. (1993). "Effect of substitution of Ca on thermal expansion of cordierite $\left(\mathrm{Mg}_{2} \mathrm{Al}_{4} \mathrm{Si}_{5} \mathrm{O}_{18}\right)$ ", J. Am. Ceram. Soc., 76(7), 1873.

[10] Yokosuka, M. (1993). "Electrical and Electromechanical properties of hot-pressed $\mathrm{Pb}\left(\mathrm{Fe}_{1 / 2} \mathrm{Nb}_{1 / 2}\right) \mathrm{O}_{3}$ ferroelectric ceramics", Jpn. J. Appl. Phys., 32, 1142.

[11] Agarwal, D. K. and Stubican, V. S. (1985). "Synthesis and sintering of $\mathrm{Ca}_{0.5} \mathrm{Zr}_{2} \mathrm{P}_{3} \mathrm{O}_{12}$-A low thermal expansion materials", Mat. Res. Bull., $20,99$.

[12] Smolensky, G. A., Agronovskaya, A. I., Popov, S. N. and Isupov, V. A. (1958). "Ferroelectrics of complex composition II: $\mathrm{Pb}_{2} \mathrm{Fe}(\mathrm{III})-\mathrm{NbO}_{6}$ and $\mathrm{Pb}_{2} \mathrm{YbNbO}_{6}$ ", Sov. PhysTech. Phys., 3, 1981.

[13] Srikanth, V. and Subbarao, E. C. (1992). "Acoustic emission in ferroelectric lead titanate ceramics: origin and recombination of microcracks", Acta Metallur. Mater. 40, 5, 1091.

[14] Sai Sunder, V. V. S. S. and Umarji, A. M. (1995). "Thermal expansion studies in the lead iron niobate-Lead titanate system", Mat. Res. Bull., 30, 4, 427.

[15] Senbhagaraman, S. (1995). Ph.D. Thesis, Indian Institute of Science, Bangalore. 

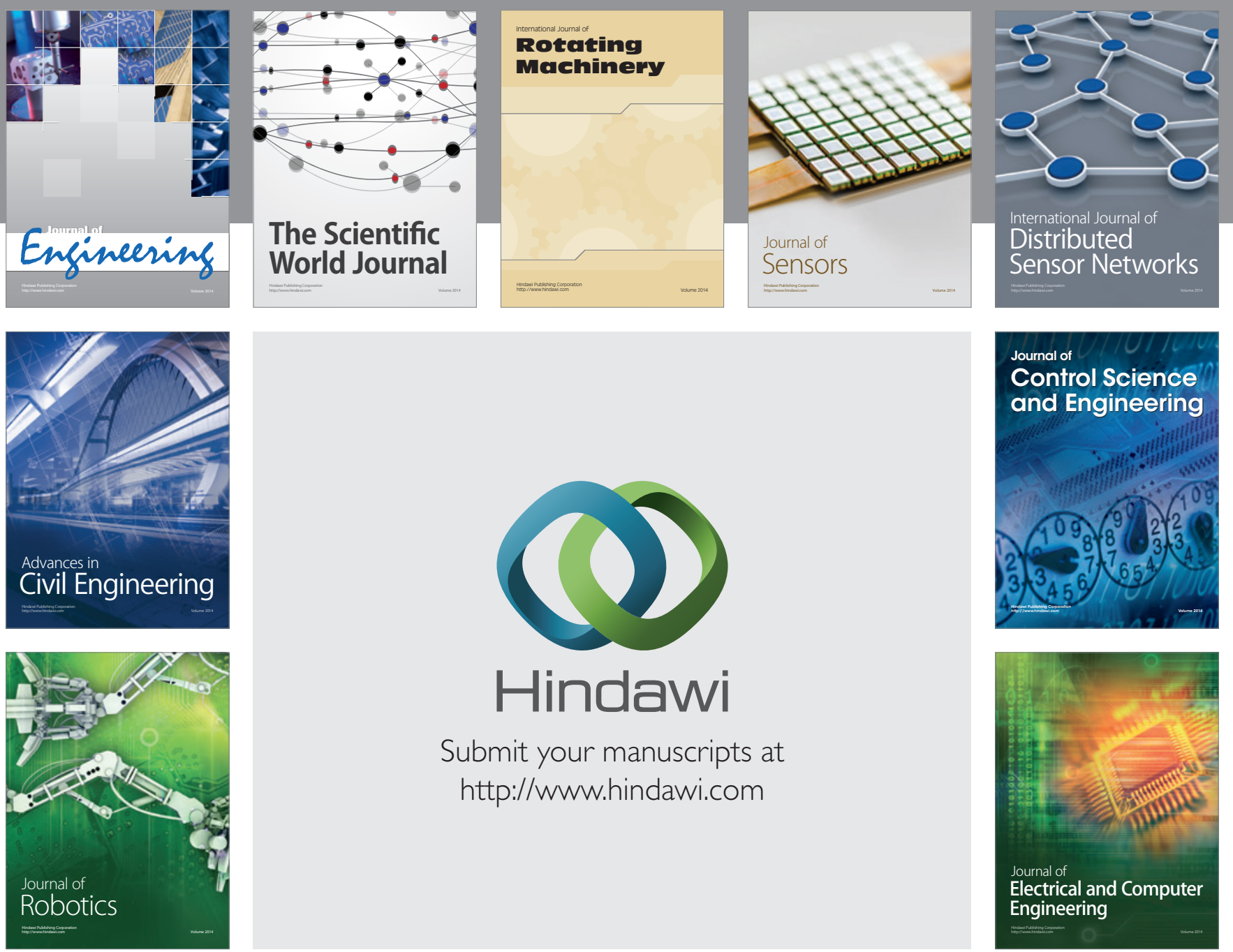

Submit your manuscripts at

http://www.hindawi.com
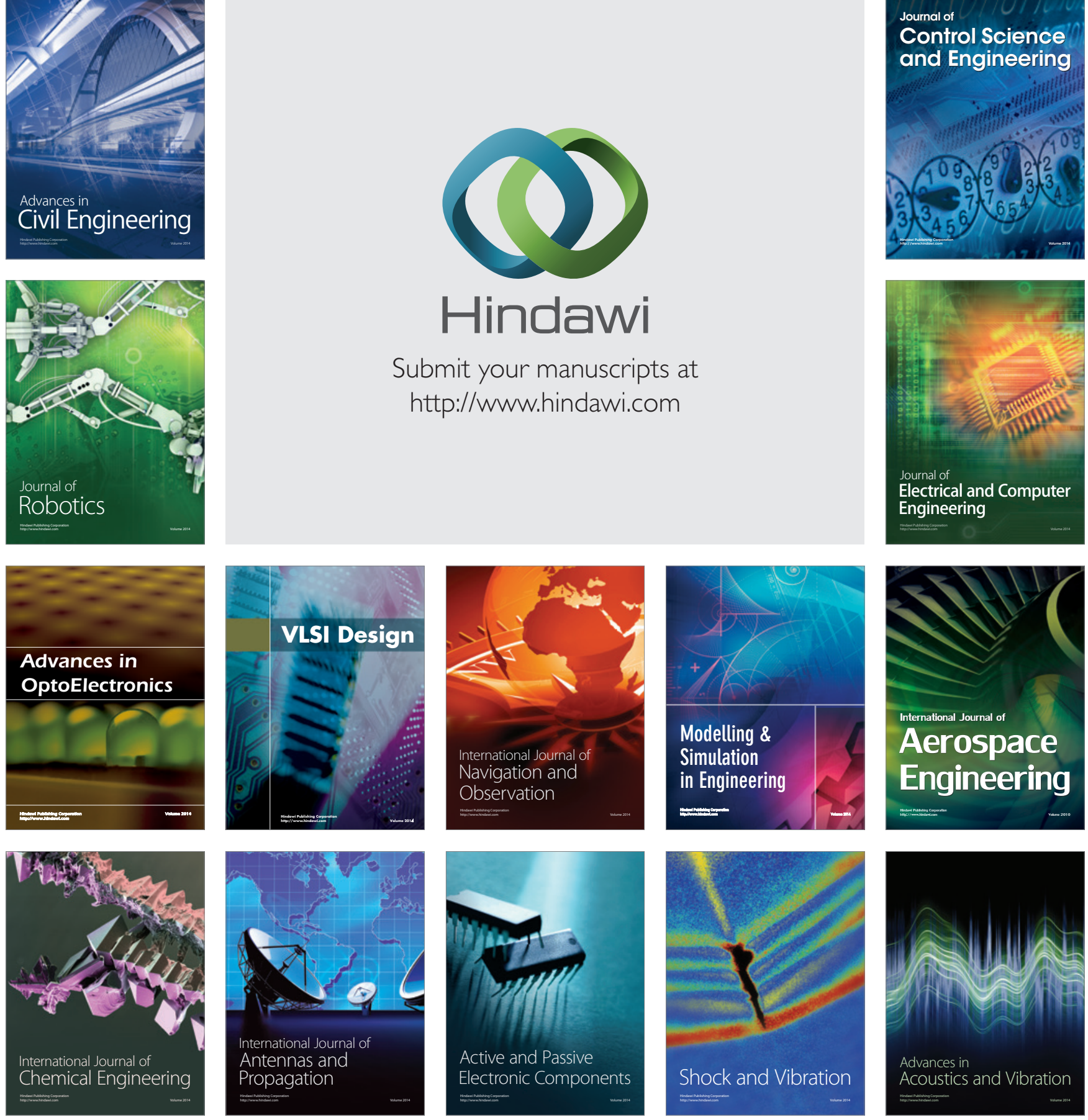